Cochrane Database of Systematic Reviews

\title{
Statin withdrawal in people with dementia (Review)
}

McGuinness B, Cardwell CR, Passmore P

McGuinness B, Cardwell CR, Passmore P.

Statin withdrawal in people with dementia.

Cochrane Database of Systematic Reviews 2016, Issue 9. Art. No.: CD012050.

DOI: 10.1002/14651858.CD012050.pub2.

www.cochranelibrary.com 
TABLE OF CONTENTS

ABSTRACT 1

PLAIN LANGUAGE SUMMARY

BACKGROUND

OBJECTIVES

METHODS

RESULTS

DISCUSSION

AUTHORS' CONCLUSIONS

ACKNOWLEDGEMENTS

REFERENCES

CHARACTERISTICS OF STUDIES

APPENDICES

CONTRIBUTIONS OF AUTHORS

DECLARATIONS OF INTEREST

SOURCES OF SUPPORT

DIFFERENCES BETWEEN PROTOCOL AND REVIEW 
[Intervention Review]

\section{Statin withdrawal in people with dementia}

Bernadette McGuinness ${ }^{1}$, Chris R Cardwell ${ }^{1}$, Peter Passmore ${ }^{1}$

${ }^{1}$ Centre for Public Health, Queen's University Belfast, Belfast, UK

Contact: Bernadette McGuinness, Centre for Public Health, Queen's University Belfast, Institute of Clinical Sciences, Block B, Grosvenor Road, Belfast, Co Antrim, BT12 6BA, UK. B.McGuinness@qub.ac.uk.

Editorial group: Cochrane Dementia and Cognitive Improvement Group.

Publication status and date: New, published in Issue 9, 2016.

Citation: McGuinness B, Cardwell CR, Passmore P. Statin withdrawal in people with dementia. Cochrane Database of Systematic Reviews 2016, Issue 9. Art. No.: CD012050. DOI: 10.1002/14651858.CD012050.pub2.

Copyright @ 2016 The Cochrane Collaboration. Published by John Wiley \& Sons, Ltd.

\section{A B S T R A C T}

\section{Background}

There are approximately 24 million people worldwide with dementia; this is likely to increase to 81 million by 2040 . Dementia is a progressive condition, and usually leads to death eight to ten years after first symptoms. End-of-life care should emphasise treatments that optimise quality of life and physicians should minimise unnecessary or non-beneficial interventions. Statins are 3-hydroxy-3methylglutaryl coenzyme A (HMG-CoA) reductase inhibitors; they have become the cornerstone of pharmacotherapy for the management of hypercholesterolaemia but their ability to provide benefit is unclear in the last weeks or months of life. Withdrawal of statins may improve quality of life in people with advanced dementia, as they will not be subjected to unnecessary polypharmacy or side effects. However, they may help to prevent further vascular events in people of advanced age who are at high risk of such events.

\section{Objectives}

To evaluate the effects of withdrawal or continuation of statins in people with dementia on: cognitive outcomes, adverse events, behavioural and functional outcomes, mortality, quality of life, vascular morbidity, and healthcare costs.

\section{Search methods}

We searched ALOIS (medicine.ox.ac.uk/alois/), the Cochrane Dementia and Cognitive Improvement Group Specialised Register on 11 February 2016. We also ran additional searches in MEDLINE, EMBASE, PsycINFO, CINAHL, Clinical.Trials.gov and the WHO Portal/ICTRP on 11 February 2016, to ensure that the searches were as comprehensive and as up-to-date as possible.

\section{Selection criteria}

We included all randomised, controlled clinical trials with either a placebo or 'no treatment' control group. We applied no language restrictions.

\section{Data collection and analysis}

Two review authors independently assessed whether potentially relevant studies met the inclusion criteria, using standard methodological procedures expected by Cochrane. We found no studies suitable for inclusion therefore analysed no data.

\section{Main results}

The search strategy identified 28 unique references, all of which were excluded.

\section{Authors' conclusions}

We found no evidence to enable us to make an informed decision about statin withdrawal in dementia. Randomised controlled studies need to be conducted to assess cognitive and other effects of statins in participants with dementia, especially when the disease is advanced. 


\section{PLAIN LANGUAGE SUMMARY}

\section{Statin withdrawal in people with dementia}

Dementia (including Alzheimer's disease) is a global healthcare concern; there are approximately 24 million people worldwide with dementia, and this is likely to increase to 81 million by 2040. Dementia is a slowly progressing condition, and persons affected may experience a gradual decline over eight to ten years. Medications that are appropriately prescribed when someone has mild dementia may no longer be appropriate as dementia progresses to severe. Statins are prescribed to lower cholesterol levels in the blood; in most cases, they help prevent myocardial infarctions (heart attacks) or strokes, but the benefits are only seen after using them for a period of months or years. They have well known side-effects, such as muscle pain, and it is not known if the benefits of these medications outweigh the risks in persons with advanced dementia.

\section{Study characteristics}

We searched several medical databases on 11 February 2016 to look for clinical trials that compared continuing a statin to withdrawing a statin, in persons with dementia.

\section{Key findings}

We found no studies that were suitable for our review. This highlights the need for further high quality research into this area. 


\section{B A C K G R O U N D}

\section{Description of the condition}

In this review, we were primarily interested in people with established dementia due to Alzheimer's disease (AD), vascular dementia (VaD) or a mix of both (mixed dementia). Other causes included dementia with Lewy bodies (DLB) and frontotemporal dementia (FTD). It is estimated there were around 850,000 people in the UK with dementia in 2015. There are approximately 24 million people worldwide with dementia, and this is likely to increase to 81 million by 2040 (Ferri 2005). It mainly affects people over the age of 65 (one in 14 people in this age group have dementia), and the likelihood of developing dementia increases significantly with age. Alzheimer's disease is the most common form of dementia, currently affecting more than 520,000 people in the UK; $\mathrm{VaD}$ is the second most common form, affecting approximately 150,000 people in the UK (Alzheimer's Society 2014). Dementia is a progressive condition and usually leads to death eight to 10 years after the first symptoms. In the later stages of the disease, people become unable to care for themselves and need help with their daily activities. End-of-life care should emphasise treatments that optimise quality of life and physicians should minimise unnecessary or non-beneficial interventions (Field 1997). Studies have shown that people with advanced dementia are more likely to be subject to polypharmacy than healthier persons with a longer life expectancy, and are at increased risk of inappropriate prescribing and adverse outcomes as a result of medications (Parsons 2015).

\section{Description of the intervention}

Statins are 3-hydroxy-3-methylglutaryl coenzyme A (HMG-CoA) reductase inhibitors. They are among the most widely prescribed medications in the USA and UK (Goldfine 2012). There are well-established benefits from this class of drugs: randomised controlled trials (RCTs) have demonstrated relative risk reductions of $20 \%$ to $30 \%$ for myocardial infarction, $20 \%$ for ischaemic stroke, and $10 \%$ to $15 \%$ for all-cause mortality (Baigent 2005). However, for most indications, the benefits of these drugs are only realised after a period of months or years (Holmes 2009). They have become the cornerstone of pharmacotherapy for the management of hypercholesterolaemia, but their ability to provide benefit is unclear in the last weeks or months of life. Older people living in residential care commonly take statins, with one study showing $33 \%$ of residents over 70 years of age were prescribed statins (Gnjiidic 2015). Continuation of statins in advanced dementia may be viewed as futile, and may contribute unnecessary distress to patients who have a high level of functional disability and eating dysfunction. Whilst many symptoms (e.g. sore throat, nosebleeds, nausea, allergic rhinitis, altered bowel habits) have been attributed to statins, the adverse effects from RCTs have generally been fewer, and include small increases in the incidence of myopathy, diabetes, and probably, hemorrhagic stroke (CTT Collaboration 2016). There is also a concern about possible cognitive harm from statins; in the USA, the Food and Drug Administration (FDA) issued new labelling rules in 2012, adding information on the potential for generally nonserious and reversible cognitive side effects. On the other hand, a network meta-analysis of 246,955 participants from 135 RCTs concluded that as a class, adverse events associated with statin therapy are not common (Naci 2013). There is a lack of evidence for cognitive benefit from statins in both treatment and prevention of dementia (McGuinness 2014; McGuinness 2016). Withdrawal of statins may improve quality of life in people with advanced dementia as they will not be subject to unnecessary polypharmacy or the side effects mentioned. However, they may help prevent further vascular events in people of advanced age who are at high risk of such events; a meta-analysis has demonstrated that each $1 \mathrm{mmol} / \mathrm{L}$ decrease in $\mathrm{LDL}$ cholesterol equates to a reduction in relative risk for stroke of $21 \%$ (Amarenco 2009).

\section{How the intervention might work}

Statin withdrawal may contribute to an improved quality of life in people with advanced dementia, which is a positive outcome, but may conversely lead to more non-fatal or fatal vascular events.

\section{Why it is important to do this review}

The value of statins in preventing heart disease and ischaemic stroke is well established. For individuals with life-limiting illness, such as advanced dementia, an expert consensus panel has suggested that certain medications, such as statins, may be inappropriate when the goal of care is comfort (Holmes 2008). Few studies have examined statin use as death approaches in advanced dementia. Prior studies of nursing-home residents with advanced dementia showed that $12 \%$ to $16 \%$ used a lipid-lowering drug, and that one-third discontinued that drug in the last weeks of life (Tjia 2010; Tjia 2014). A prospective cohort study of medication in National Health residents with advanced dementia found a significant number of people were still being prescribed statins towards the end of their life (Blass 2008), while In a recent feasibility study, a consensus panel of expert clinicians from Northern Ireland rated the use of statins as never appropriate in advanced dementia (Parsons 2015). Statins also frequently contribute to polypharmacy, which in itself has been shown to increase mortality in nursinghome residents with advanced cognitive impairment at the end of life (Onder 2013). One study group has advocated that in the absence of a recent acute coronary syndrome or cerebrovascular event, the discontinuation of a statin towards the end of life is reasonable (Vollrath 2005). It may be the case that a watershed moment is reached, when the disease reaches a threshold of severity, and the risks outweigh the benefits of the medications (Bowman 2014). Due to the frequency with which statins are prescribed to people with advanced dementia, there is a need for further research into the benefits, risks, and effects on quality of life if these medications are to be discontinued towards the end of life.

\section{O B JECT IVES}

To evaluate the effects of withdrawal or continuation of statins in people with dementia on: cognitive outcomes, adverse events, behavioural and functional outcomes, mortality, quality of life, vascular morbidity, and healthcare costs.

\section{METHODS}

\section{Criteria for considering studies for this review}

\section{Types of studies}

All randomised, controlled clinical trials. We included withdrawal trials that were not placebo-controlled, and evaluated them for bias. We applied no language restrictions. 


\section{Types of participants}

- All people with a diagnosis of dementia, as defined by a recognised and validated tool or clinical assessment, and taking any type of statin. Eligible dementia subtypes are AD, VaD, mixed dementia, DLB and FTD.

- People with a diagnosis of probable or possible AD, according to National Institute of Aging-Alzheimer's Association 2011 criteria (McKhann 2011), or acceptable equivalent.

- People with a diagnosis of probable or possible VaD, according to National Institute of Neurological Disorders and Stroke/ Association Internationale pour la Recherché et l'Enseignement en Neurosciences (NINDS-AIREN) criteria (Román 1993), or acceptable equivalent.

- People with a diagnosis of probable or possible DLB, according to international consensus criteria for DLB (McKeith 2005).

- People with a diagnosis of probable or possible FTD according to Neary criteria (Neary 1998).

Participants may reside in any healthcare setting, including acute hospitals, nursing and residential homes and the community.

\section{Types of interventions}

Intervention: Withdrawal or dose reduction of statin or placebo.

Comparison: Continuation of statin.

\section{Types of outcome measures}

\section{Primary outcomes}

- Cognition (Mini Mental State Examination (MMSE) or equivalent).

- Adverse effects of statin medications.

\section{Secondary outcomes}

- Function (Barthel Activities of Daily Living or equivalent), behaviour, mortality, vascular morbidity (stroke, myocardial infarction (MI)), and quality-of-life outcomes, measured with validated scales.

- Hospitalisation.

\section{Search methods for identification of studies}

\section{Electronic searches}

We searched ALOIS (www.medicine.ox.ac.uk/alois/), the Cochrane Dementia and Cognitive Improvement Group (CDCIG) Specialised Register on 11 February 2016. We went through all possible statin withdrawal trials to identify any that had cognitive outcomes.

ALOIS is maintained by the Information Specialist for the Cochrane Dementia and Cognitive Improvement Group, and contains studies that fall within the areas of dementia prevention, dementia treatment and management, and cognitive enhancement in healthy elderly populations. The studies are identified through:

1. Monthly searches of a number of major healthcare databases: MEDLINE, EMBASE, CINAHL, PsycINFO and LILACS;

2. Monthly searches of a number of trial registers: International Standard Randomised Controlled Trials Number (ISRCTN); UMIN (Japan's Trial Register); the WHO portal (which covers ClinicalTrials.gov; ISRCTN; the Chinese Clinical Trials Register; the German Clinical Trials Register; the Iranian Registry of Clinical Trials and the Netherlands National Trials Register, plus others);

3. Quarterly search of the Cochrane Central Register of Controlled Trials (CENTRAL);

4. Six-monthly searches of a number of grey literature sources: ISI Web of Knowledge Conference Proceedings; Index to Theses; Australasian Digital Theses.

To view a list of all sources searched for ALOIS see About ALOIS.

Details of the search strategies run in healthcare bibliographic databases, used for the retrieval of reports of dementia, cognitive improvement, and cognitive enhancement trials, can be viewed in the 'Methods used in reviews' section within the editorial information about the Cochrane Dementia and Cognitive Improvement Group.

We ran additional searches in MEDLINE, EMBASE, PsycINFO, CINAHL, Clinical.Trials.gov, and the WHO Portal/ICTRP on 11 February 2016, to ensure that the searches were as comprehensive and as up-to-date as possible. The search strategy that we used for the retrieval of reports of trials from MEDLINE (via the Ovid SP platform) can be seen in Appendix 1.

\section{Searching other resources}

We reviewed citations of reference lists of included studies identified through the search strategy described above, and assessed their suitability for inclusion in the review. We did not apply any language restrictions.

\section{Data collection and analysis}

We designed the methods in this review in accordance with recommendations in the Cochrane Handbook for Systematic Reviews of Interventions (Higgins 2011).

\section{Selection of studies}

Two review authors (BMcG and PP) independently screened titles and abstracts. Both review authors agreed on and tested the MeSH terms and search strategy. They both independently selected trials for relevance against the defined inclusion criteria. They retrieved in full text any papers identified as potentially relevant by at least one review author; both review authors independently reviewed the papers against the inclusion criteria, and reached a final decision through consensus. We listed all papers excluded from the review at the full-text stage as excluded studies, with reasons provided in the 'Characteristics of excluded studies' table. We did not identify any ongoing RCTs that met our inclusion criteria. In future updates of this review, we will employ the methods detailed in the 'Differences between protocol and review' section below.

\section{Data extraction and management}

Not applicable

\section{Assessment of risk of bias in included studies}

Not applicable

\section{Measures of treatment effect}

Not applicable 


\section{Unit of analysis issues}

Not applicable

\section{Dealing with missing data}

Not applicable

\section{Assessment of heterogeneity}

Not applicable

\section{Assessment of reporting biases}

Not applicable

Data synthesis

Not applicable

\section{Subgroup analysis and investigation of heterogeneity}

Not applicable

\section{Sensitivity analysis}

Not applicable

\section{RE S U L T S}

\section{Description of studies}

Not applicable

\section{Results of the search}

Electronic searches retrieved 28 abstracts. We obtained four full papers in full-text form. No studies were eligible for inclusion.

\section{Included studies}

No studies met our inclusion criteria.

\section{Excluded studies}

We excluded four studies after examination of the full text (Padala 2010; Padala 2012; Tjia 2014; Kutner 2015). See also the 'Characteristics of excluded studies' table.

Padala 2010 was a retrospective chart review carried out on 55 patients with dementia or mild cognitive impairment who were receiving statin treatment at the initial visit. Twenty-four subjects had their statin discontinued at the initial visit; they had a MMSE at baseline but only eighteen had a repeat MMSE at follow-up. Mean length of follow-up was 4.8 weeks, SD 1.4 weeks.There was an apparent improvement in cognition in those who stopped taking statins, but there were no MMSE scores provided for those who continued taking statins, so a direct comparison was not available. The study was not randomised, included no cognitive information on the control group, was not blinded, had a short duration, and small sample size, so was not suitable for inclusion in the review.

Padala 2012 was a twelve-week prospective open-label study. Eighteen older subjects with Alzheimer's disease underwent a sixweek withdrawal phase from statins, followed by a six-week rechallenge. This pilot study showed an improvement in cognition, as measured by the MMSE, with discontinuation of statins and worsening with re-challenge. The study was not randomised, included no control group, was not blinded, had a small sample size, and short duration, so was not suitable for inclusion.

Tjia 2014 was a retrospective inception cohort study, therefore, did not meet inclusion criteria for this review. There were no cognitive or adverse effect outcomes reported. Nursing home residents with advanced dementia were observed from baseline and followed for at least ninety days to statin discontinuation or death. In followup, $37.2 \%$ of nursing home residents with advanced dementia discontinued statins. Median time to discontinuation was 36 days (interquartile range 12 to 110 days). Shorter time to discontinuation was associated with hospitalisation in the past thirty days, and more daily medications.

Kutner 2015 was a multicenter, parallel-group, unblinded pragmatic clinical trial with 381 participants. Eligible participants were English speaking adults (at least 18 years old) receiving a statin for at least three months, for primary or secondary prevention of cardiovascular disease. Eligible participants had a documented diagnosis of advanced, life-limiting illness, determined by (1) at least one physician indicating he or she 'would not be surprised if the patient died in the next year', (2) life expectancy between one month and one year, and (3) recent deterioration in functional status. Participants were randomised to either discontinue or continue statin therapy, and were monitored monthly for up to one year. Twenty-seven per cent of the statin discontinuation group and $17.2 \%$ of the statin continuation group were cognitively impaired at baseline. There was no subgroup analysis carried out in those who were cognitively impaired, so the study did not meet inclusion criteria for this review; the study authors were contacted, but could not provide data on the cognitively impaired subgroup.

\section{Risk of bias in included studies}

No study met the eligibility criteria

\section{Effects of interventions}

No study met the eligibility criteria

\section{DISCUSSION}

\section{Summary of main results}

There were no clinical trials suitable for inclusion in this review, highlighting the need for further research in this area. Controversy remains regarding the use of statins in people with advanced dementia. Four studies were excluded due to study design. Randomised controlled double-blind studies with a larger sample size and a longer duration need to be conducted to assess the cognitive effects of statins in participants with dementia, especially when the disease is advanced.

\section{Overall completeness and applicability of evidence}

There were no randomised controlled trials, so evidence is lacking.

\section{Quality of the evidence}

No studies met the inclusion criteria for this review, so there is no evidence to assess.

\section{Potential biases in the review process}

Our search terms did not include some recent favoured terminologies such as deprescribing, and there are no specific 
search filters related to deprescribing; this is something we will work on for future reviews.

We were unable to check for publication bias, as we did not find any studies that met our inclusion criteria.

\section{Agreements and disagreements with other studies or reviews}

Other reviews have assessed the impact of statin treatment on cognition in general (Richardson 2013; Kelley 2014; Ott 2015), but none have assessed statin withdrawal in participants with dementia.

\section{AUTHORS' CONCLUSIONS}

\section{Implications for practice}

We are unable to make any evidence-based recommendations, as we found no suitable studies that assessed the impact of statin withdrawal in patients with dementia.

\section{Implications for research}

High quality RCTs are required in this area, whereby patients with advanced dementia are randomised so that the intervention is withdrawal of the statin and continuation of the usual statin is the control. Ideally, studies should assess the impact of statin withdrawal on cognition, adverse effects, and other secondary outcomes, such as physical function, behaviour, mortality, vascular morbidity, quality of life, and hospitalisation rate. Prior studies have reported that more than $90 \%$ of proxies of nursing home residents with advanced dementia state that their goal of care is comfort (Luchins 1993; Mitchell 2009). Statins do not promote comfort, so their role in the case of advanced dementia may not be warranted, but evidence is lacking. A further trial will most likely require government or charity funding, as statin manufacturers are unlikely to fund such a trial. If it is proven that withdrawal of statins is of benefit in advanced dementia, the money saved could be used in effective but underused interventions, thereby contributing towards affordable healthcare.

\section{ACK N O WLEDGEMENTS}

The authors would like to thank the Cochrane Dementia and Cognitive Improvement group editorial team for their support in writing this review. 


\section{R E F E R E N C E S}

\section{References to studies excluded from this review}

\section{Kutner 2015 \{published data only\}}

Kutner JS, Blachford PJ, Taylor Jr DH, Ritchie CS, Bull JH, Fairclough DL, et al. Safety and Benefit of Discontinuing Statin Therapy in the Setting of Advanced, Life-Limiting Illness. A Randomized Clinical Trial. JAMA Intern Med 2015;175:691-700.

Padala 2010 \{published data only\} Padala KP, Padala PR, Potter JF. Statins: A case for drug withdrawal in patients with dementia. JAGS 2010;6:1214-1216.

Padala 2012 \{published data only\}

Padala KP, Padala PR, McNeilly DP, Geske JA, Sullivan DH, Potter JF. The Effect of HMG-CoA Reductase Inhibitors on Cognition in Patients with Alzheimer's Dementia: A Prospective Withdrawal and Rechallenge Pilot Study. The American Journal of Geriatric Pharmacotherapy 2012;10:296-302.

\section{Tjia 2014 \{published data only\}}

Tjia J, Cutrona SL, Peterson D, Reed G, Andrade SE, Mitchell SL. Statin Discontinuation in Nursing Home Residents with Advanced Dementia. Journal of the American Geriatrics Society 2014;62:2095-2101.

\section{Additional references}

\section{Alzheimer's Society 2014}

Dementia UK: Update Second edition, November 2014. Available from alzheimers.org.uk/dementiauk (accessed on 10/12/2015)

\section{Amarenco 2009}

Amarenco P, Labreuche J. Lipid management in the prevention of stroke; review and updated meta-analysis of statins for stroke prevention. Lancet Neurology 2009;8(5):453-63.

\section{Baigent 2005}

Baigent C, Keech A, Kearney PM, Blackwell L, Buck G, Pollicino C, et al. Cholesterol Treatment Trialists' (CTT) Collaborators. Efficacy and safety of cholesterol-lowering treatment: prospective meta-analysis of data from 90,056 participants in 14 randomised trials of statins. Lancet 2005;366(9493):1267-78.

\section{Blass 2008}

Blass DM, Black BS, Philips H, Finucane T, Baker A, Loreck D, et al. Medication use in nursing home residents with advanced dementia. International Journal of Geriatric Psychiatry 2008;23(5):490-6.

\section{Bowman 2014}

Bowman C, Meyer J. Formative care: defining the purpose and clinical practice of care for the frail. Journal of the Royal Society of Medicine 2014;107(3):95-8.

\section{CTT Collaboration 2016}

Cholesterol Treatment Trialists' (CTT) Collaboration. Protocol for analyses of adverse event data from randomized controlled trials of statin therapy. American Heart Journal 2016;176:63-9.

\section{Ferri 2005}

Ferri CP, Prince M, Brayne C, Brodaty H, Fratiglioni L, Ganguli M, et al. Alzheimer's Disease International. Global prevalence of dementia: a Delphi consensus study. Lancet 2005;366(9503):2112-7.

\section{Field 1997}

Field M, Cassell C. Institute of Medicine Report. Approaching Death: Improving Care at the End of Life. Washington, DC: National Academy Press, 1997.

\section{Gnjiidic 2015}

Gnjiidic D, Wilson N, March L, Cumming RG, Cameron ID, Hilmer SN. Statin utilisation patterns in older Australians living in residential care: 1-year prevalence study. Internal Medicine Journal 2015;45:106-9.

\section{Goldfine 2012}

Goldfine AB. Statins: is it really time to reassess benefits and risks?. New England Journal of Medicine 2012;366(19):1752-5.

\section{GRADEproGDT 2015 [Computer program]}

McMaster University, developed by GRADE Working Group and Evidence Prime, Inc.. GRADEpro GDT: GRADEpro Guideline Development Tool. Available from: gradepro.org. Version (accessed on 22/12/2015). Hamilton, ON: McMaster University, developed by GRADE Working Group and Evidence Prime, Inc., 2015.

\section{Higgins 2011}

Higgins JPT, Green S (editors). Cochrane Handbook for Systematic Reviews of Interventions Version 5.1.0 [updated March 2011]. The Cochrane Collaboration, 2011. Available from handbook.cochrane.org.

\section{Holmes 2008}

Holmes HM, Sachs GA, Shega JW, Hougham GW, Cox Hayley D, Dale W, et al. Integrating palliative medicine into the care of persons with advanced dementia: identifying appropriate medication use. Journal of the American Geriatrics Society 2008;56(7):1306-11.

\section{Holmes 2009}

Holmes HM. Rational prescribing for patients with a reduced life expectancy. Clinical Pharmacology and Therapeutics 2009;85(1):103-7.

\section{IQWIG 2015}

Institut für Qualität und Wirthschaftlichkeit im Gesundheitswesen. General Methods. Available from iqwig.de/download/IQWiG_General_Methods_Version_ \%204-1.pdf 2015 (accessed 6 January 2016). 


\section{Kelley 2014}

Kelley BJ, Glasser S. Cognitive Effects of Statin Medications. CNS Drugs 2014;28:411-419.

\section{Luchins 1993}

Luchins DJ, Hanrahan P. What is appropriate health care for end-stage dementia?. Journal of the American Geriatrics Society 1993;41:25-30.

\section{McGuinness 2014}

McGuinness B, Craig D, Bullock R, Malouf R, Passmore P. Statins for the treatment of dementia. Cochrane Database of Systematic Reviews 2014, Issue 7. [DOI: 10.1002/14651858.CD007514.pub3]

\section{McGuinness 2016}

McGuinness B, Craig D, Bullock R, Passmore P. Statins for the prevention of dementia. Cochrane Database of Systematic Reviews 2016, Issue 1. [DOI: 10.1002/14651858.CD003160.pub3]

\section{McKeith 2005}

McKeith IG, Dickson DW, Lowe J, Emre M, O'Brien JT, Feldman H, et al. DLB Consortium. Diagnosis and management of dementia with Lewy bodies: Third report of the DLB consortium. Neurology 2005;65(12):1863-72.

\section{McKhann 2011}

McKhann GM, Knopman DS, Cherthow H, Hyman BT, Jack CR Jr, Kawas $\mathrm{CH}$, et al. The diagnosis of dementia due to Alzheimer's disease: recommendations from the National Institute on Aging-Alzheimer's Association workgroups on diagnostic guidelines for Alzheimer's disease. Alzheimers \& Dementia 2011;7(3):263-9.

\section{Mitchell 2009}

Mitchell SL, Teno JM, Kiely DK, Shaffer ML, Jones RN, Prigerson HG, et al. The clinical course of advanced dementia. New England Journal of Medicine 2009;361:1529-38.

\section{Naci 2013}

Naci H, Brugts J, Ades T. Comparative tolerability and harms of individual statins: a study-level network meta-analysis of 246955 participants from 135 randomized, controlled trials. Circulation. Cardiovascular Quality and Outcomes 2013;6(4):390-9.

\section{Neary 1998}

Neary D, Snowden JS, Gustasfson L, Passant U, Stuss D, Black S, et al. Frontotemporal lobar degeneration: a consensus on clinical diagnostic criteria. Neurology 1998;51(6):1546-54.

\section{Onder 2013}

Onder G, Liperoti R, Foebel A, Fialova D, Topinkova E, van der Roest HG, et al. SHELTER Project. Polypharmacy and mortality among nursing home residents with advanced cognitive impairment: results from the SHELTER study. Journal of the American Medical Directors Association 2013;14(6):450.e7-12.

\section{Ott 2015}

Ott BR, Daiello LA, Dahabreh IJ, Springate BA, Bixby K, Murali M, Trikalinos TA. Do statins impair cognition? A systematic review and meta-analysis of randomized controlled trials. J Gen Intern Med 2015;30:348-58.

\section{Parsons 2015}

Parsons C, McCann L, Passmore P, Hughes C. Development and application of medication appropriateness indicators for persons with advanced dementia: a feasibility study. Drugs \& Aging 2015;32(1):67-77.

\section{RevMan 2014 [Computer program]}

The Nordic Cochrane Centre, The Cochrane Collaboration. Review Manager (RevMan). Version 5.3. The Nordic Cochrane Centre, The Cochrane Collaboration, 2014.

\section{Richardson 2013}

Richardson K, Schoen M, French B, Umscheid CA, Mitchell MD, Arnold SE, Heidenreich PA, Rader DJ, deGoma EM. Statins and Cognitive Function. A Systematic Review. Annals of Internal Medicine 2013;159:688-697.

\section{Román 1993}

Román GC, Tatemichi TK, Erkinjuntti T, Cummings JL, Masdeu JC, Garcia JH, et al. Vascular dementia: diagnostic criteria for research studies. Report of the NINDS-AIREN international workshop. Neurology 1993;43(2):250-60.

\section{Rucker 2008}

Rücker G, Schwarzer G, Carpenter JR, Schumacher M. Undue reliance on I(2) in assessing heterogeneity may mislead. BMC Medical Research Methodology 2008;8:79.

\section{Schünemann 2011}

Schünemann H, Hill S, Guyatt G, Akl EA, Ahmed F. The GRADE approach and Bradford Hill's criteria for causation. Journal of Epidemiology and Community Health 2011;65(5):392-5.

\section{Spiegelhalter 2004}

Spiegelhalter DJ. Monitoring Clinical Performance: A commentary. The Journal of Thoracic and Cardiovascular Surgery 2004;128:820-2.

\section{Sterne 2011}

Sterne JAC, Egger M, Mother D (editors). Chapter 10: Addressing reporting biases in: Higgins JPT, Green S (editors). Cochrane Handbook for Systematic Reviews of Interventions Version 5.1.0 [Updated March 2011]. The Cochrane Collaboration, 2011. Available from handbook.cochrane.org.

\section{Tjia 2010}

Tjia J, Rothman MR, Kiely DK, Shaffer ML, Holmes HM, Sachs GA, et al. Daily medication use in nursing home residents with advanced dementia. Journal of the American Geriatrics Society 2010;58(5):880-8.

\section{Vollrath 2005}

Vollrath AM, Sinclair C, Hallenbeck J. Discontinuing cardiovascular medications at the end of life: lipid lowering medications. Journal of Palliative Medicine 2005;8(4):876-81. 


\section{CHARACTERISTICS OF STUDIES}

Characteristics of excluded studies [ordered by study ID]

\begin{tabular}{ll}
\hline Study & Reason for exclusion \\
\hline Kutner 2015 & $\begin{array}{l}\text { No cognitive or adverse effects outcomes. 27\% of participants in the discontinuation group and } \\
17.2 \% \text { in the continuation of statins group were cognitively impaired, but there was no subgroup } \\
\text { analysis carried out. }\end{array}$ \\
\hline Padala 2010 & Retrospective case note study. \\
\hline Padala 2012 & Not randomised, no control group, not blinded. \\
\hline Tjia 2014 & Retrospective inception cohort study. \\
\hline
\end{tabular}

\section{APPENDICES}

\section{Appendix 1. MEDLINE search strategy}

1. (statin or statins).ti,ab.

2. atorvastatin.ti,ab.

3. cerivastatin.ti,ab.

4. fluvastatin.ti,ab.

5. lovastatin.ti,ab.

6. pravastatin.ti,ab.

7. simvastatin.ti,ab.

8. lipitor.ti,ab.

9. baycol.ti,ab.

10. lescol.ti,ab.

11. mevacor.ti,ab.

12. altocor.ti,ab.

13. pravachol.ti,ab.

14. lipostat.ti,ab.

15. zocor.ti,ab.

16. mevinolin.ti,ab.

17. compactin.ti,ab.

18. fluindostatin.ti,ab.

19. rosuvastatin.ti,ab.

20. Hydroxymethylglutaryl-CoA Reductase Inhibitors/ or Lovastatin/ 
21. Simvastatin/

22. or/1-21

23. randomized controlled trial.pt.

24. controlled clinical trial.pt.

25. randomized.ab.

26. placebo.ab.

29. drug therapy.fs.

30. randomly.ab.

31. trial.ab.

32. groups.ab.

33. or/44-52

34. (animals not (humans and animals)).sh.

35. 32 not 33

36.22 and 34

37. discontinu*.mp.

38. withdraw*.mp.

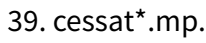

40. (reduce* or reducing* $^{\star}$ or reduct ${ }^{\star}$ ).mp.

41. taper ${ }^{\star} . \mathrm{mp}$.

42. stop $^{\star} \cdot \mathrm{mp}$.

43. "carry on".mp.

44. continu*.mp.

45. maintain ${ }^{\star} . \mathrm{mp}$.

46. remain*.mp.

47. or/35-46

48. 35 AND 47

\section{CONTRIBUTIONS OF AUTHORS}

BMcG: all work concerned with the review

PP: selection of studies, commenting on draft review

CC: Statistical advice, commenting on draft review

\section{DECLARATIONS OF INTEREST}

BMcG: none known

PP: none known

CC: none known 


\section{SOURCES OF SUPPORT}

\section{Internal sources}

- No sources of support supplied

\section{External sources}

- NIHR, UK.

This review was supported by the National Institute for Health Research, via a Cochrane Programme Grant to the Cochrane Dementia and Cognitive Improvement group. The views and opinions expressed therein are those of the authors and do not necessarily reflect those of the Systematic Reviews Programme, NIHR, NHS or the Department of Health

\section{DIFFERENCES BETWEEN PROTOCOLANDREVIEW}

\section{Assessment of risk of bias in included studies}

Two review authors (BMcG and PP) will independently assess risk of bias for each of the included studies, using the criteria outlined in the Cochrane Handbook for Systematic Reviews of Interventions (Higgins 2011). We will resolve any disagreements by discussion, or if necessary, we will involve the third review author (CC). We will assess the following domains: selection bias, performance bias, detection bias, attrition bias, and reporting bias. We will carry out sensitivity analyses to determine inclusion or exclusion of low-quality studies.

\section{(1) Random sequence generation (checking for possible selection bias)}

We will describe for each included study the method used to generate the allocation sequence in sufficient detail to allow an assessment of whether it should produce comparable groups.

We will assess the risk of bias for sequence generation as:

- low risk (any truly random process, e.g. random-number table; computer random-number generator);

- high risk (any non-random process, e.g. odd or even date of birth; hospital or clinic record number);

- unclear risk.

\section{(2) Allocation concealment (checking for possible selection bias)}

We will describe for each included study the method used to conceal allocation to interventions prior to assignment and will assess whether intervention allocation could have been foreseen in advance of or during recruitment, or changed after assignment.

We will assess the risk of bias for allocation concealment as:

- low risk (e.g. telephone or central randomisation; consecutively-numbered sealed opaque envelopes);

- high risk (e.g. open random allocation; unsealed or non-opaque envelopes; alternation; date of birth);

- unclear risk.

\section{(3.1) Blinding of participants and personnel (checking for possible performance bias)}

We will describe for each included study the methods used, if any, to blind study participants and personnel to knowledge of which intervention a participant received. We will consider that studies are at low risk of bias if they were blinded.

We will assess the risk of bias for blinding of participants and personnel as:

- low, high or unclear risk of bias for participants;

- low, high or unclear risk of bias for personnel.

\section{(3.2) Blinding of outcome assessment (checking for possible detection bias)}

We will describe for each included study the methods used, if any, to blind outcome assessors to knowledge of which intervention a participant received.

We will assess the risk of bias for blinding of outcome assessment as:

- low risk;

- high risk;

- unclear risk. 
(4) Incomplete outcome data (checking for possible attrition bias due to the amount, nature, and handling of incomplete outcome data)

We will describe for each included study, and for each outcome, the completeness of data including attrition and exclusions from the analysis. We will state whether attrition and exclusions were reported, the numbers included in the analysis at each stage (compared with the total number of randomised participants), reasons for attrition or exclusion where reported, and whether missing data were balanced across groups or were related to outcomes. Where sufficient information is reported, or can be supplied by the trial authors, we will reinclude missing data in the analyses that we undertake. We will assess the risk of bias for incomplete outcome data as:

- low risk (e.g. no missing outcome data; missing outcome data balanced across groups);

- high risk (e.g. frequency of or reasons for missing data that are unbalanced across groups);

- unclear risk.

\section{(5) Selective reporting (checking for reporting bias)}

We will investigate the possibility of selective outcome reporting bias by cross-checking outcomes of interest reported in the Methods section to those reported in the Results section of the trial publications. We will assess the risk of bias for selective reporting as:

- low risk (where it is clear that all of the prespecified outcomes and all expected outcomes of interest to the review have been reported);

- high risk (where not all the prespecified outcomes have been reported; one or more reported primary outcomes were not prespecified; outcomes of interest are reported incompletely and so cannot be used; study fails to include results of a key outcome that would have been expected to have been reported);

- unclear risk.

(6) Other bias (checking for bias due to problems not covered by (1) to (5) above)

We will describe for each included study any important concerns we have about other possible sources of bias.We will assess the risk of other forms of bias as:

- low risk;

- high risk;

- unclear risk.

\section{(7) Overall risk of bias}

We will make explicit judgements about whether studies are at high risk of bias, according to the criteria given in theCochrane Handbook for Systematic Reviews of Interventions (Higgins 2011). With reference to (1) to (6) above, we will assess the likely magnitude and direction of the bias and whether we consider it is likely to impact the findings. We will explore the impact of the level of bias by undertaking sensitivity analyses (see Sensitivity analysis), and we will assess the overall risk of bias for each included study as:

- low risk;

- high risk;

- unclear risk.

\section{Measures of treatment effect}

Continuous data: We will extract the mean change from baseline, the standard error of the mean change, and the number of participants for each treatment group at each assessment. Where change from baseline is not reported, we will extract the mean, standard deviation (SD), and the number of participants for each treatment group at each time point. We will also extract available data on demographics of participants (age, gender, lipid values at baseline), statin regimen (type of statin, daily dosage, starting time, duration), and follow-up duration. We will report the difference, mean, and 95\% confidence interval $(\mathrm{Cl})$.

Dichotomous data: For binary data (e.g. statin or not), we will seek the numbers in each treatment group and the numbers experiencing the outcome of interest. We will report results as an odds ratio (OR) with $95 \% \mathrm{Cl}$.

We will use the GRADE approach to assess the quality of the supporting evidence behind each estimate of treatment effect (Schünemann 2011). We will present key findings of the review, including a summary of the amount of data, the magnitude of the effect size, and the overall quality of the evidence, in a 'Summary of findings' table, created using GRADEpro software (GRADEproGDT 2015). We have preselected the following outcomes: cognition, function, behaviour, mortality, vascular morbidity, and quality of life. 


\section{Unit of analysis issues}

Studies with multiple treatment groups: If a study involves more than two treatment groups, we will exclude any treatment groups not relevant to the review objectives. If more than two groups are relevant to a single meta-analysis, we will combine groups to form single experimental and control groups.

\section{Dealing with missing data}

For included studies, we will note levels of attrition. We will explore the impact of including studies with high levels of missing data (we judge this a priori to be greater than $20 \%$ for a primary outcome) in the overall assessment of treatment effect by conducting a sensitivity analysis.

For all outcomes, we will carry out analyses as far as possible on an intention-to-treat basis. If intention-to-treat data are not available in the publications, we will use complete-case data, i.e. the data for those who completed the trial. If neither intention-to-treat nor completecase data are available, we will use 'on-treatment' data, and will make this clear.

\section{Assessment of heterogeneity}

Where studies are considered similar enough (based on consideration of populations and interventions) to allow pooling of data using meta-analysis, we will assess the degree of heterogeneity by visual inspection of forest plots and by examining the Chi ${ }^{2}$ test for heterogeneity. We will assess statistical heterogeneity in each meta-analysis using the $\mathrm{I}^{2}$ and $\mathrm{Chi}^{2}$ statistics. With regard to statistical heterogeneity, we will rate an $I^{2}$ statistic of up to $30 \%$ as possibly not important, of $30 \%$ to $60 \%$ as moderate, $50 \%$ to $90 \%$ as substantial, and $75 \%$ to $100 \%$ as considerable (IQWIG 2015). We will prefer tau ${ }^{2}$ over $I^{2}$ in the interpretation of between-trial heterogeneity, as the interpretation of $\mathrm{I}^{2}$ can be largely affected by the precision of trials included in the meta-analysis (Rucker 2008). We pre specify a Tau ${ }^{2}$ of 0.04 to represent low heterogeneity, 0.09 to represent moderate heterogeneity, and 0.16 to represent high heterogeneity between trials (Spiegelhalter 2004).

Where we identify substantial clinical, methodological, or statistical heterogeneity across included studies, we will consider whether it is appropriate to report a pooled effect result from the meta-analysis, or to use a narrative approach to synthesise data. In this event, we will attempt to explore possible reasons for the heterogeneity by grouping studies that have similar populations and interventions.

\section{Assessment of reporting biases}

If there are 10 or more studies in the meta-analysis, we will investigate reporting biases (such as publication bias) using funnel plots. We will visually assess funnel plot asymmetry. If this suggests asymmetry, we will perform exploratory analyses to investigate it. We acknowledge that publication bias may not be the only cause of funnel plot asymmetry. If a small-study effect is apparent, we will explore other potential reasons, for example diversity in methodological quality, bias, and genuine heterogeneity in the intervention effect. We will investigate other possible causes by undertaking a sensitivity analysis (Sterne 2011).

We will also verify trial details and outcomes against trial descriptions identified in trial registries.

\section{Data synthesis}

We will carry out statistical analysis using the Review Manager 5 software (RevMan 2014). If there is clinical heterogeneity sufficient to expect that the underlying treatment effects differ between trials, or if we detect substantial statistical heterogeneity (Tau ${ }^{2}$ greater than 0.16 ), we will use a random-effects model meta-analysis to produce an overall summary, provided that we consider an average treatment effect across trials to be clinically meaningful. We will treat the random-effects model summary as the average treatment effect, and we will discuss the clinical implications of treatment effects differing between trials. If the average treatment effect is not clinically meaningful, we will not combine trials.

If we use random-effects model analyses, we will present the results as the average treatment withdrawal effect with a $95 \% \mathrm{Cl}$ and with the estimate of $\mathrm{Tau}^{2}$ and $\mathrm{I}^{2}$.

We will only use a fixed-effect model meta-analysis for combining data where it is reasonable to assume that studies are estimating the same underlying treatment effect, i.e. where we judge participants, interventions, and methods to be sufficiently similar.

\section{Subgroup analysis and investigation of heterogeneity}

Where data are available, we will conduct an analysis based on relevant and clinically meaningful subgroups such as class of statins (lipophilic versus hydrophilic); low versus high doses of statins; and duration of use: short-term use (less than one month of cumulative use), intermediate-term use (one month or more, but less than 24 months of cumulative use); and long-term use (more than two years cumulative use).

We will conduct an analysis based on the degree of dementia severity: severe, moderate, or mild as defined by clinical judgement or MMSE cut-off scores (less than 12, 12 to 20, more than 20/30 respectively). Where this is not explicit, we will request data on severe or not severe from study authors. 
We will assess subgroup differences by interaction tests available within RevMan 2014. We will report the results of subgroup analyses quoting the $\mathrm{Chi}^{2}$ statistic and $\mathrm{P}$ value, and the interaction test $\mathrm{I}^{2}$ value.

\section{Sensitivity analysis}

If heterogeneity persists with either model, we will carry out a sensitivity analysis (excluding studies with a high risk of bias), thereby assessing the robustness of the results. 